\title{
The contours and consequences of compassion at work
}

\author{
JACOBA M. LILIUS ${ }^{1 *}$, MONICA C. WORLINE ${ }^{2}$, SALLY MAITLIS ${ }^{3}$, \\ JASON KANOV ${ }^{4}$, JANE E. DUTTON ${ }^{5}$ AND PETER FROST ${ }^{3}$ \\ ${ }^{1}$ School of Policy Studies, Queen's University, Kingston, Ontario, Canada \\ ${ }^{2}$ Goizueta Business School, Emory University, Atlanta, Georgia, U.S.A. \\ ${ }^{3}$ Sauder School of Business, University of British Columbia, Vancouver, BC, Canada \\ ${ }^{4}$ College of Business and Economics, Western Washington University, Bellingham, Washington, U.S.A. \\ ${ }^{5}$ Stephen M. Ross School of Business, University of Michigan, Michigan, U.S.A.
}

Summary This paper describes two studies that explore core questions about compassion at work. Findings from a pilot survey indicate that compassion occurs with relative frequency among a wide variety of individuals, suggesting a relationship between experienced compassion, positive emotion, and affective commitment. A complementary narrative study reveals a wide range of compassion triggers and illuminates ways that work colleagues respond to suffering. The narrative analysis demonstrates that experienced compassion provides important sensemaking occasions where employees who receive, witness, or participate in the delivery of compassion reshape understandings of their co-workers, themselves, and their organizations. Together these studies map the contours of compassion at work, provide evidence of its powerful consequences, and open a horizon of new research questions. Copyright (C) 2008 John Wiley \& Sons, Ltd.

One of our employees' husbands was very ill, close to death. They had to take several trips to the University Hospital as well as trips out of state for his medical care. The department got together and gave gas cards, phone cards, money, pop, food, puzzles to do while she stays with him, just all kinds of stuff. Everyone was very concerned for her and her family. I think that was compassion at its ultimate. The great thing is that is only one of many stories from our department. I chose only one.

$\sim$ Gail, account supervisor

I was chewed out by a cardiologist on the unit because a patient had an (unusual) rhythm. The previous RN reported to me that the cardiology group was aware of this rhythm and chose not to do anything. I tried to explain this to the cardiologist but she said, "I don't care what the night shift told you!!” I also was reprimanded in front of other staff \& physicians by this doctor. . .my manager's office is on the unit, and I saw her door open. I just walked in the office, sat down and cried. She took time out of her schedule to talk with me and encourage me. She also followed up with the previous

* Correspondence to: Jacoba M. Lilius, School of Policy Studies, Queen's University, 138 Union St., Room 319, Kingston, Ontario, Canada E-mail: jacoba.lilius@queensu.ca 
$\mathrm{RN}$, the cardiologist and the night-level coordinator to figure out what had happened. This was very much appreciated and she helped me to feel very cared about.

$\sim$ Jennifer, nurse

\section{Introduction}

Suffering is an inevitable part of organizational life. Defined as the experience of pain that evokes existential anguish (Reich, 1989), suffering springs from many sources outside and within organizations. For example, illness, injury, or death of loved ones can cause pain that spills into the workplace (Harvey, 2001), as in Gail's story above. It can also arise within an organization as a result of toxic interactions with bosses, colleagues, or customers (Frost, 2003) as in Jennifer's story, from organizational processes that generate pain (Maitlis \& Ozcelik, 2004), or in carrying out the "necessary evils" of work organizations, which unavoidably cause harm to others at work (Molinsky \& Margolis, 2005). These psychologically painful experiences have a significant impact on both employees and organizations, as reflected in a recent finding from the Grief Recovery Institute showing that firms lose more than $\$ 75$ billion annually from employees' grief-related incidents (Zaslow, 2002). As our opening stories suggest, compassion shown by work colleagues can strengthen emotional connections at work and boost people's ability to function as productive employees (Dutton, Frost, Worline, Lilius \& Kanov, 2002; Frost, Dutton, Worline \& Wilson, 2000). Building from stories such as those told by Gail and Jennifer, this paper explores the contours and consequences of compassion at work.

Although the study of compassion has a long tradition in religion, medicine, and sociology, it has a relatively short history in organizational behavior (Frost et al., 2006). Only recently have we begun to learn about the positive effects of compassion at work or the organizational conditions under which it arises. The impact of compassion was initially revealed by employees who described how valued and connected they felt after receiving compassionate acts from others in the organization (Dutton et al., 2002; Frost et al., 2000). Using an in-depth case study to examine the occurrence of a large-scale compassionate response, Dutton, Worline, Frost, and Lilius (2006) showed that whether the social coordination of compassion is activated and mobilized depends on an organization's social architecture and the agency of those in the organization. Despite these insights, many questions about the nature and impact of compassion at work still remain unanswered, such as the kinds of suffering that trigger acts of compassion at work, who gives and receives it, the different forms compassion takes in organizations, and consequences for those who receive, witness, or participate in delivery of compassion.

In the present paper, we begin to address these questions through two complementary studies. In so doing, we surface the painful situations that are part of the tapestry of everyday organizational life and illuminate the informal kinds of compassionate responses that often go unnoticed by those further from the site of suffering. These studies together result in a view of the deep connections that exist in work organizations but are often missed in studies that regard workplaces simply as sites of economic transactions or task and service execution.

\section{Distinguishing Compassion at Work}

Following Clark (1997) and Davis (1983), we understand compassion as a multi-dimensional process in which three elements of compassion form a tri-partite concept: noticing another person's suffering, 
empathically feeling that person's pain, and acting in a manner intended to ease the suffering (Dutton et al., 2006; Kanov et al., 2004; Miller, 2007). All of these elements are necessary, in this view, to understand compassion. Importantly, compassion goes beyond felt empathy to entail action, which is regarded as a compassionate response regardless of whether or not it successfully alleviates suffering (Kanov et al., 2004; Reich, 1989; Soygal Rinpoche, 1992).

A key assumption underlying this conceptualization, and as will be revealed in this study, is that a compassionate response may take a wide range of forms, such as gestures of emotional support, giving material goods, or providing a colleague with work flexibility. As a function of this range, compassion is related to, yet distinct from, several other constructs of interest to organizational researchers. In particular, a compassionate response may take the shape of emotional or material social support (House, 1981), prosocial behavior (Brief \& Motowildo, 1986) or organizational citizenship behavior (OCB) (Smith, Organ, \& Near, 1983) yet is not limited to any one of these forms, representing the full range of responses to human suffering. For example, while emotional social support has been defined as "talking, listening, and expressing concern or empathy" (Zellars \& Perrewe, 2001, p. 459), compassionate responses often extend far beyond empathetic conversations, and can entail significant allocations of material and instrument resources directed toward persons in pain (Dutton et al., 2006). An additional distinguishing feature is that compassion is preceded by suffering and is driven by felt empathetic concern, while these related forms of workplace helping do not necessarily involve an empathetic response to suffering. Finally, compassion can be conceived as one form of caregiving among co-workers (Kahn, 1993), but one that it is also found outside organizations designed explicitly for caregiving purposes (Kahn, 1993, 1998, 2005). We argue that compassion is prevalent in a variety of organizations, precisely because it is a response to the inevitable pain of human existence (Frost, 2003; Frost et al., 2006).

This paper presents two exploratory studies that address core questions about the contours and consequences of compassion at work: a pilot survey that captures the nature of compassion at work and its relationship to key affective outcomes and a narrative analysis of stories of compassion at work that provides further insight into what compassion at work means for employees. These combined methods portray a deepened image of the kinds of suffering experienced, and responses offered, in the workplace. The studies also provide insight into the affective experience of compassion, the sensemaking that takes place in its presence or absence, and the wider implications of compassion for other work outcomes.

\section{Study 1: A Pilot Survey of Compassion at Work}

Our pilot survey had two goals: (1) to document the range, frequency, and sources of compassion at work, and (2) to gather empirical evidence for the theorized relationship between the frequency of work compassion, positive emotion, and affective commitment.

\section{Theory and hypotheses}

Previous research has documented the critical role of felt empathetic concern in driving compassionate responses in organizations (Dutton et al., 2006). Because of the inherently emotional nature of compassion at work, we expected that the experience of compassion would have particularly strong associations with affective outcomes such as felt positive emotion on the job and affective organizational commitment. We draw upon the framework provided by affective events theory (Weiss 
\& Cropanzano, 1996), which suggests that strong emotional events at work spark additional emotion, shape momentary action, and create an ongoing emotional tone in the workplace. Affective events theory also suggests that such emotions and their associations can accumulate over time to contribute to stable work-related attitudes. We suggest that instances of compassion at work are likely to stand out as salient affective events, and as such may generate additional emotions, shape behaviors, and contribute to longer-term affective variables. In keeping with the tenets of affective event theory, described below are hypotheses related to the affective impact of compassion at work.

\section{Compassion and positive emotion}

Several research streams suggest a relationship between compassion at work and positive emotion (Dutton, 2003; Folkman \& Moskowitz, 2000; Frost, 2003; Hallowell, 1999; Kahn, 1993, 1998). The giving and receiving of compassion may be construed as an important affective event in the workplace, triggering further positive emotion (Weiss \& Cropanzano, 1996). When people receive compassion, it is thought to increase feelings of connection with one another, which in turn produces a variety of positive feelings (Dutton, 2003; Miller \& Stiver, 1997). Compassion also helps those experiencing personal difficulty find positive meaning in an otherwise painful event, which in turn cultivates positive emotions (Folkman \& Moskowitz, 2000; Fredrickson, Tugade, Waugh, \& Larkin, 2003). Following this, we predict that the experience of compassion will be associated with more frequent positive emotions at work.

Hypothesis 1. There will be a positive relationship between experienced compassion at work and the frequent inducement of positive emotion at work.

\section{Compassion and affective commitment}

Our second hypothesis stems from research that suggests a relationship between compassion and affective commitment, a positive emotional attachment to one's organization that results in part from experiences at work (Meyer \& Allen, 1991). Following the affective events theory framework (Weiss \& Cropanzano, 1996), we suggest that experiences of compassion may be particularly salient emotional events that prompt positive feelings about the organization. Individuals are drawn to sources of positive emotion, such as groups that are successful or induce positive emotions like pride (Cialdini et al., 1976). Similarly, positive construals of one's own organization as supportive have been shown to lead to greater affective commitment to the organization (Rhoades, Eisenberger, \& Armeli, 2001). In addition, compassion may strengthen commitment to the organization through perceptions of being valued and cared about by the organization, which encourages the incorporation of organizational membership into the employee's self-identity (Meyer \& Allen, 1991). Finally, since compassion in the workplace is often directed towards someone who is struggling with non-work related issues, compassion may help employees balance work and personal life, reducing inter-role conflict, and strengthening affective commitment (Allen, 2001). Thus, we hypothesize that experienced compassion at work will strengthen employees' affective commitment.

Hypothesis $2 a$. There will be a positive relationship between experienced compassion at work and affective organizational commitment.

Working at the intersection of affective events theory in organizations (Weiss \& Cropanzano, 1996) and Fredrickson's (1998) broaden-and-build theory of positive emotion, we suggest that frequent positive emotion triggered by compassion at work will mediate the relationship between experienced compassion at work and affective commitment to the organization. Broaden-and-build theory suggests that in the presence of positive emotion at work, people experience an expanded thought-action 
repertoire, broadened mindsets, and enhanced openness (Fredrickson, 1998, 2003). According to this view, as people experience compassion at work, they will also experience positive emotion that enhances their openness and reflects well on their organization. Affective events theory suggests that employees may use the experience of compassion as a salient event that triggers felt positive emotion and momentary actions and meanings, which can accumulate to form longer-term attitudes (Weiss \& Cropanzano, 1996). Thus, frequent experiences of positive emotion at work arising from experienced compassion may lead to pleasant emotional associations with the workplace and accumulate over time into strengthened affective commitment to the organization (Fisher, 2002; Weiss \& Cropanzano, 1996; Fredrickson, 1998).

Hypothesis $2 b$. There will be a positive relationship between experienced compassion at work and affective organizational commitment through the frequent inducement of positive emotion at work.

\section{Methods}

\section{Research setting and participants}

This research was performed at Fairview ${ }^{1}$ hospital, a large community hospital in a mid-sized urban area in the central United States (see Appendix A for further contextual information). We distributed research materials to all 2400 hospital employees throughout patient care and administration using the organization's payroll distribution network, arriving at employees' workstations on 6 September 2001 with a request to return the materials via mail by 30 September 2001. A total of 239 employees completed and returned the survey, representing a 10 per cent response rate. Eighty-five percent of the respondents were women, with an average age of 42 years and average organizational tenure level of 9.5 years. Of those respondents who indicated their supervisory positions, half reported no supervisory role in the organization, with the next largest group (14 per cent) reporting that they supervised 1-5 employees. With respect to education, the vast majority of the sample had either an associates' ( 29 per cent) or bachelor's ( 29 percent) degree, with the other 25 percent reporting a high school education and 15 percent advanced degrees. Data provided by the human resources department at Fairview hospital indicated that participants' demographic profile parallels the overall population of the organization, which has 83 per cent female employees, an average age of 42.8 years, average tenure of 8.7 years, and 6 per cent in supervisory roles. Of the nursing population, 71 per cent hold an associates' degree, 25 per cent hold a bachelors degree, and 4 per cent hold advanced degrees; modal education information for other populations was not available. Respondents also provided information about their work unit, which we coded into three broad categories: those working in medical/surgical (44 per cent), outpatient services (28 per cent), and administrative units (28 per cent). Follow-up interviews with the Vice President of Human Resources (VPHR) indicated that these proportions closely matched the broader organizational structure.

Fostering research participation. The research team undertook substantial efforts to maximize response rates through notification of the upcoming research via the hospital's bimonthly newsletter and an introductory letter encouraging participation co-signed by the senior researcher and the VPHR. We also organized an activity dubbed "CompassionFest," in which research team members staffed tables in central hospital locations for 5 days to encourage participation in a variety of ways (e.g., offering information, extra survey copies, candy, and chances to enter a drawing for gift certificates).

\footnotetext{
${ }^{1}$ The identities of the research setting and of all respondents have been disguised to protect research participant confidentiality.
} 
A few days following distribution of our study materials, the terrorist attacks of 11 September 2001 occurred, which had direct and indirect effects on the employees of Fairview Hospital. As research team members visited the organization each day from 11 to 14 September, it was clear that questions about compassion in the workplace seemed eclipsed by the sweeping need for compassion on a much wider scale. While these events significantly stunted our response rates, they also deepened our conviction about the importance of this topic. Although the survey response was disappointing by conventional standards, since respondents were representative of the organizational population we argue that, as a pilot study, these findings provide valuable insights that move us toward an understanding of the contours and consequences of compassion at work.

\section{Measures}

Survey items were based on either 5 -point Likert-type frequency scales $(1=$ never, $5=$ nearly all the time) or 7 -point Likert-type agreement scales $(1=$ strongly disagree, $7=$ strongly agree). Composite index variables were formed for all scales by averaging across items.

Experienced compassion. We measured experienced compassion at work using three items written specifically for this study. Respondents indicated on a 5-point Likert-type scale how frequently they experienced compassion: (a) on the job, (b) from their supervisor, and (c) from their co-workers. Because of our interest in understanding what individuals experienced as compassion, and our desire not to restrict their thinking to only certain kinds of behavior, we chose not to define compassion for them in the survey. A factor analysis of these items confirmed adequate unidimensionality (eigenvalue $=2.10,70$ per cent of variance explained; factor loadings greater than 0.80 ) and reliability of the composite scale was acceptable $(\alpha=0.79)$. This measure serves as a pilot measure of the experience of compassion at work, as we could access no previously established or validated measures.

Positive emotion. We used a modified version of Izard's (1977) emotions scale to measure frequency of positive emotion, asking respondents to rate the frequency with which they felt four emotions during a typical week at work: (1) proud; (2) grateful; (3) inspired; and (4) at ease. A composite index reflected overall frequency of positive emotion, and factor analysis supported a single-factor solution (eigenvalue $=2.78$ with 70 per cent of variance explained; all factor loadings greater than 0.80$)$ and reliability of the composite scale was acceptable $(\alpha=0.85)$.

Affective commitment. We assessed affective organizational commitment using six items from the Affective Commitment Scale (ACS; Allen \& Meyer, 1990). A seventh item was removed as suggested by Culpepper (2000) to improve construct measurement. The composite index had high reliability $(\alpha=0.90)$ and factor analysis suggested unidimensionality (eigenvalue $=4.10,68$ per cent of variance explained; all factor loadings greater than 0.75). An example item is: "I do not feel like "part of the family' at my organization" (reverse coded).

\section{Analytic strategy}

The principal analyses consisted of structural equation modeling using the EQS program (Bentler, 1995), a technique which provides simultaneous estimation of the hypothesized regressions using the covariance matrix generated, based on the observed covariance matrix of the measured variables, and used for evaluating the goodness-of-fit between the data and the model. In reporting these results, we follow the guidelines suggested by Raykov, Tomer, and Nesselroade (1991) and report the following measures: normed fit index (NFI), non-normed fit index (NNFI), comparative fit index (CFI), as well as the misfit measure known as root-mean-square error of approximation (RMSEA; Hu \& Bentler, 1999). Indications for acceptable fit are provided by indices that exceed 0.90 and misfit RMSEA index under 0.06. All composite reliabilities exceeded 0.70 , suggesting that the specified indicators were sufficient. 
Table 1. Descriptive statistics and correlations

\begin{tabular}{|c|c|c|c|c|c|c|c|}
\hline Variable & Mean & SD & $n$ & 1 & 2 & 3 & 4 \\
\hline 1. Age & 42.43 & 10.74 & 220 & & & & \\
\hline 2. Tenure & 9.50 & 8.66 & 227 & $.511^{* * *}$ & & & \\
\hline 3. Compassion & 3.52 & .80 & 237 & .052 & -.077 & & \\
\hline 4. Positive emotion & 3.52 & .76 & 236 & $.157^{*}$ & .038 & $.596^{* * *}$ & \\
\hline 5. Affective commitment & 4.71 & 1.36 & 239 & $.204^{* *}$ & .114 & $.579^{* * *}$ & $.712^{* * *}$ \\
\hline
\end{tabular}

${ }^{*} p<.05 ;{ }^{* *} p<.01 ;{ }^{* * *} p<.001$.

\section{Results}

We present descriptive statistics including scale means, standard deviations, and intercorrelations of all continuous variables in Table 1. Reports of experienced compassion frequency ran the full range of possible responses from 1 (never) to 5 (always) $(M=3.62 ; \mathrm{SD}=0.79)$. Participants report receiving compassion more frequently from co-workers than from supervisors $(t(230)=46.58, p<.001)$. There were no significant differences in the frequency of experienced compassion by age, gender, education, tenure, or level in the organization. Of particular note is that people who responded "never" or "rarely" to questions regarding frequency of compassion had a similar demographic (average age of 45 years, 78 percent female, and 57 percent reporting "college or bachelor's degree") and organizational profile (average organizational tenure of 9.39 years, and 58 percent reporting no supervisory role). Distribution within unit type, however, differed slightly, with 75 percent of respondents working in medical/surgical units. This difference was reflected in the finding that unit type was related to the frequency of compassion, reported as significantly less in medical/surgical units than in administrative or outpatient units $(F(2,191)=10.45, p<.001)$.

\section{Hypothesis testing}

The measurement model represents a confirmatory factor analysis of all scales used in the study, and indicated excellent fit $\left(\chi^{2}(24)=31.12, \mathrm{NFI}=0.97 ; \mathrm{NNFI}=0.99 ; \mathrm{CFI}=0.99 ; \mathrm{RMSEA}=0.04\right)$. Table 2 presents the $\chi^{2}$ values, associated degrees of freedom, CFI, and RMSEA for model comparisons, and indicates that the theoretical model (Model 1) fit the data well. To examine the validity of the hypothesized effects, we compared the theoretical model with the structural null model (Model 2) and two alternative models: one in which positive emotion is a full mediator of the relationship between compassion and affective commitment (Model 3), and one which shows frequency of compassion and positive emotion as related but making independent contributions to affective commitment (Model 4). As shown in Table 2, alternative model indices for each indicated greatly reduced fit and increased levels of error. Thus, we maintained the theoretical model in which the

Table 2. Model comparisons

\begin{tabular}{llrrrr}
\hline Model & Description & $\chi^{2}$ & $\mathrm{~d} f$ & RMSEA & CFI \\
\hline Model 1 & Hypothesized model & 71.97 & 24 & 0.05 & 0.99 \\
Model 2 & Structural null model & 313.80 & 27 & 0.22 & 0.74 \\
Model 3 & Positive emotion as full mediator & 39.01 & 25 & 0.08 & 0.96 \\
Model 4 & Compassion and emotion as independent & 60.71 & 25 & 0.14 & 0.91 \\
& predictors of affective commitment & & & & \\
\hline
\end{tabular}




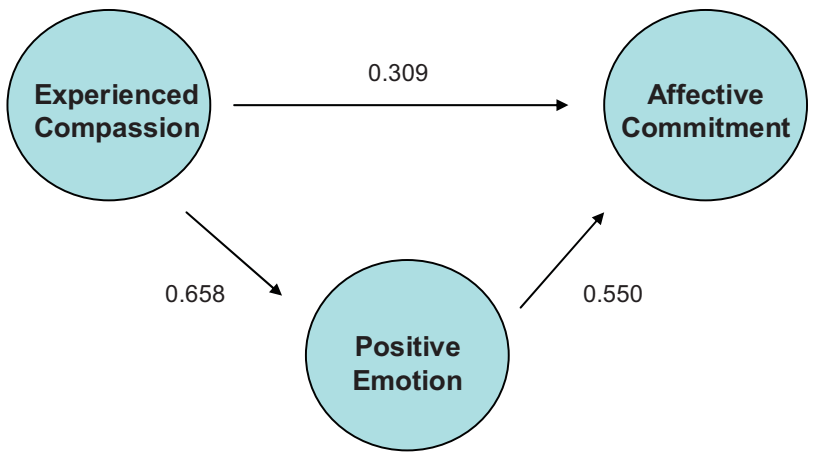

Figure 1. Structural equation model of the effects of experienced compassion at work. $\chi^{2}(48)=71.97$. Normed, non-normed, and comparative fit indexes are $0.96,0.98$, and 0.99 , respectively, with RMSEA $=0.05$. All parameter estimates shown are significant $(p<.01)$

frequency of compassion is related to affective commitment partly through its relationship with positive emotion.

The standardized path coefficients for our theoretical model, presented in Figure 1, provided further support for our hypotheses. The model shows strong support for the relationship between experienced compassion at work and experienced positive emotion, supporting Hypothesis 1. Experienced compassion at work and positive emotion were both related to higher levels of affective commitment, supporting Hypothesis $2 \mathrm{a}$ and $\mathrm{b}$.

\section{Discussion}

Study 1 provides, to our knowledge, the first evidence that experiencing compassion at work is important for positive emotion and affective organizational commitment and suggests that the effect of experienced compassion is not only a momentary affective event but also accumulates to leave a lasting trace on organization members. These findings, though preliminary, also suggest that there is meaningful variation in the experience of compassion in the workplace. While people on average reported experiencing compassion between "sometimes" and "often" on our pilot scales, some respondents ( 9 per cent) who did not differ demographically from the larger sample in any significant way reported rarely or never experiencing compassion on the job. This distribution indicates the variability that exists in people's experience of compassion, and provides some evidence that the sample was not a self-selected group that responded only because they had experienced compassion.

This pilot survey revealed some interesting patterns in the occurrence of compassion. First, participants reported experiencing compassion more frequently from co-workers than from supervisors, a noteworthy finding in light of research indicating the importance of supervisors as a source of support through their greater access to resources ( $\mathrm{Lim}, 2005)$. This suggests that there may be less tangible sources of support to which co-workers have access and are thus able to provide for their colleagues. The sources of experienced compassion at work and the implications for supervisory and co-worker relationships bear further scrutiny. In addition, despite the intuition that an employee with more subordinates might have more people interested in their welfare, in this sample, compassion was experienced with equal frequency among those who do and do not manage other employees. This finding challenges the idea that those in positions of lesser power, who must often pay more attention to those in positions of power (Fiske \& Depret, 1999), will also provide more compassion to those in upper level management positions. 
Finally, compassion was reported as least frequent in units that perform direct patient care as opposed to administrative or outpatient units, which runs counter to the intuition that those involved in the "business of care" would be more adept at or more likely to offer compassion and raises questions about how different organizational contexts might facilitate or inhibit the expression of compassion. Given what is known about the culture of occupational groups such as physicians and surgeons, where feeling rules demand resilience and self-reliance (Rafaeli \& Sutton, 1987; Smith \& Kleinman, 1989), it is perhaps unsurprising that those in the medical/surgical units in our study reported less frequent compassion than others. At the same time, previous research indicates that compassion can be found in unexpected contexts, such as a business school or a news agency (Dutton et al., 2006; Dutton et al., 2002). It is also possible that the lower frequency of compassion in the direct patient care units resulted from the "compassion burnout" commonly found in the helping professions (Figley, 1995; Rainer, 2000). This suggests an intriguing avenue for future research that addresses the influence of occupational and organizational culture in the enactment of compassion at work.

\title{
Study 2: Stories Reveal the Contours of Compassion at Work
}

The second part of our program of exploratory research is a narrative study that provides a richer description of the texture and consequences of compassion at work. This study had four goals: (1) to identify the types of suffering that trigger compassionate responses among work colleagues; (2) to identify which colleagues respond to those triggers and the forms of these responses; (3) to uncover the emotional tone of people's descriptions of compassion at work; and (4) to begin to understand how people make sense of compassion in their everyday work.

\section{Methods}

\section{Measures: using stories as data}

Research materials for the narrative study consisted of a one-page story solicitation included in the same sealed envelope as the survey materials and read as follows: "Please provide a story of a time when you either (a) experienced compassion at work, or (b) witnessed compassion at work," with blank space for each respondent to write a story. Stories convey everyday life as it is lived in a particular moment, freezing activity within a snapshot that researchers can use as a depiction of work life (Bruner, 1986; Ochs \& Capps, 2001). Besides their capacity to capture the everyday realities of people's work, stories are an important aspect of research on compassion at work because they capture and convey emotion (Riessman, 1993). Writers such as Leguin (1969/1976) have also noted that stories allow us to enter the worlds rendered by others and understand the feelings and experiences of people outside of ourselves. Because they capture everyday reality, are vehicles for emotion, and provide a window into how people make sense of their experience, we use stories as a form of data that is particularly well-suited to render a textured description of the experience of compassion at work.

\begin{abstract}
Analytic strategy
We first coded each story for basic narrative characteristics such as who narrates the story, the actors involved, and the point of view of the storyteller vis a vis compassion (i.e., compassion witness, giver, or recipient). Using a counting and coding strategy from content analysis research (Krippendorf, 2004) and similar to the open coding procedure suggested by Strauss and Corbin (1998), we counted instances of a range of key concepts stemming from the goals of the study, documenting presence or absence, as well as categorizing stories that contained similar ideas. For example, to depict the types of suffering
\end{abstract}


that trigger compassion at work, we coded each story for the presence or absence of a pain trigger, and then developed a comprehensive set of categories of pain triggers described in the sample of stories. We conducted similar coding for the forms of compassion. We coded each story for the presence of particular emotion words, using the words that are included in the circumplex model of emotion (Russell, 1980) as a guide. This is a conservative way of coding for emotion, as we did not use interpretive coding for the emotion carried in the story, but simply coded for outright mentions of emotion. Finally, in order to examine the sensemaking contained in each story, we conducted an analysis that captured the types of inferences that people made about the meaning of compassion as it related to themselves, their co-workers, and their organization.

\section{Analysis}

Of the 239 participants who returned the survey, 159 provided us with one or more stories of compassion at work, yielding a total of 171 stories available for analysis. Of these, 5 per cent $(N=9)$ were stories that indicated a lack of compassion. In the analyses, we separate the non-compassion stories from those that described instances of compassion $(N=162)$ and report on these stories separately. The demographics and survey responses of those who did versus did not provide a story did not differ significantly. For all of the coding described below, two independent coders categorized the data, and the independent coder ratings were used to calculate Cohen's Kappa, a measure of inter-rater reliability that corrects for the amount of agreement that would occur by chance (see Cohen, 1960). Across all categories, Cohen's Kappa indicated that the coding was highly reliable, with an average of $\kappa=0.83$.

\section{Types of suffering that trigger compassion}

Table 3 shows the types of suffering described in the stories. The largest category ( 44 per cent) is the illness of oneself or a loved one. The next largest category (17 per cent) involves the death of a family member or friend. Family issues, divorce, and financial difficulties are the triggers for compassion in 15 per cent of the stories. As a function of the context within which the study was conducted, we expected to find some stories of compassion related to patient care. Nine percent of the stories described suffering when the employee was a patient of the hospital or a patient's family member, and 15 per cent of the stories described interactions with patients in the hospital. Work stress in the hospital setting was the trigger for compassion in 5 per cent of the stories, and included organizational sources of pain such as uncivil behavior from work colleagues and workplace injury. The remaining 15 per cent of the stories fell into a general category of "other," including triggers that did not make up 5 per cent or more of the sample.

\section{Providers and recipients of compassion at work}

The vast majority of stories ( 80 per cent) describe compassion as being coordinated among several co-workers or an entire unit of staff. Only 10 per cent of the stories describe a single individual as the compassion provider, and 7 per cent describe compassion solely from a supervisor.

We further coded each story for the point of view of its narrator as: (1) a recipient of compassion; (2) a witness to compassion; or (3) a participant in delivering compassion. Table 4 shows that the majority of stories ( 52 per cent) are told from the perspective of a recipient of compassion, 38 per cent from the perspective of a compassion witness, and only 13 percent from the perspective of someone participating in the delivery of compassion.

Considering the health care context in which we were studying compassion, we compared stories that involved patient care to those that involved co-worker interactions. Table 4 shows that among 


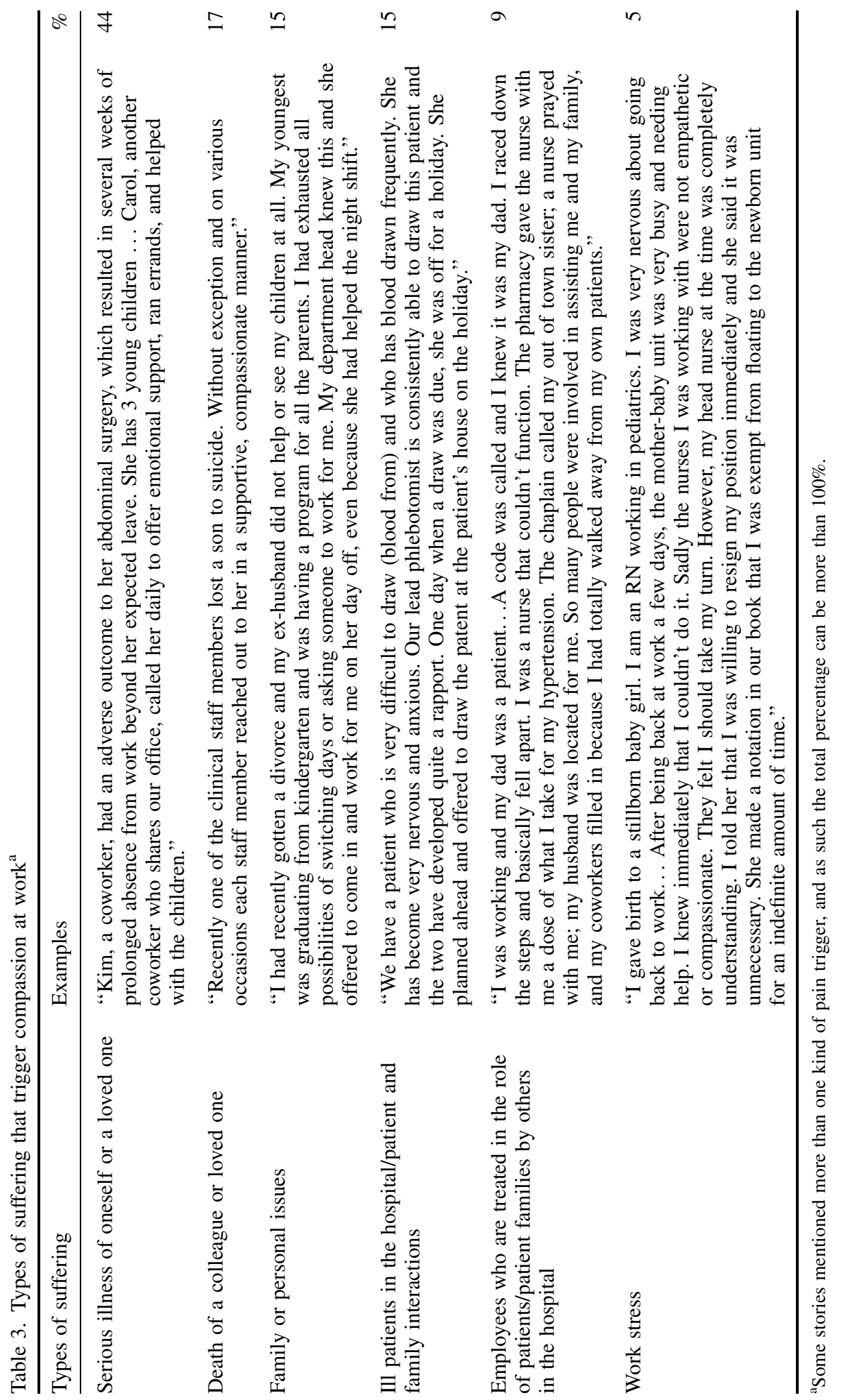

Copyright (C) 2008 John Wiley \& Sons, Ltd. 


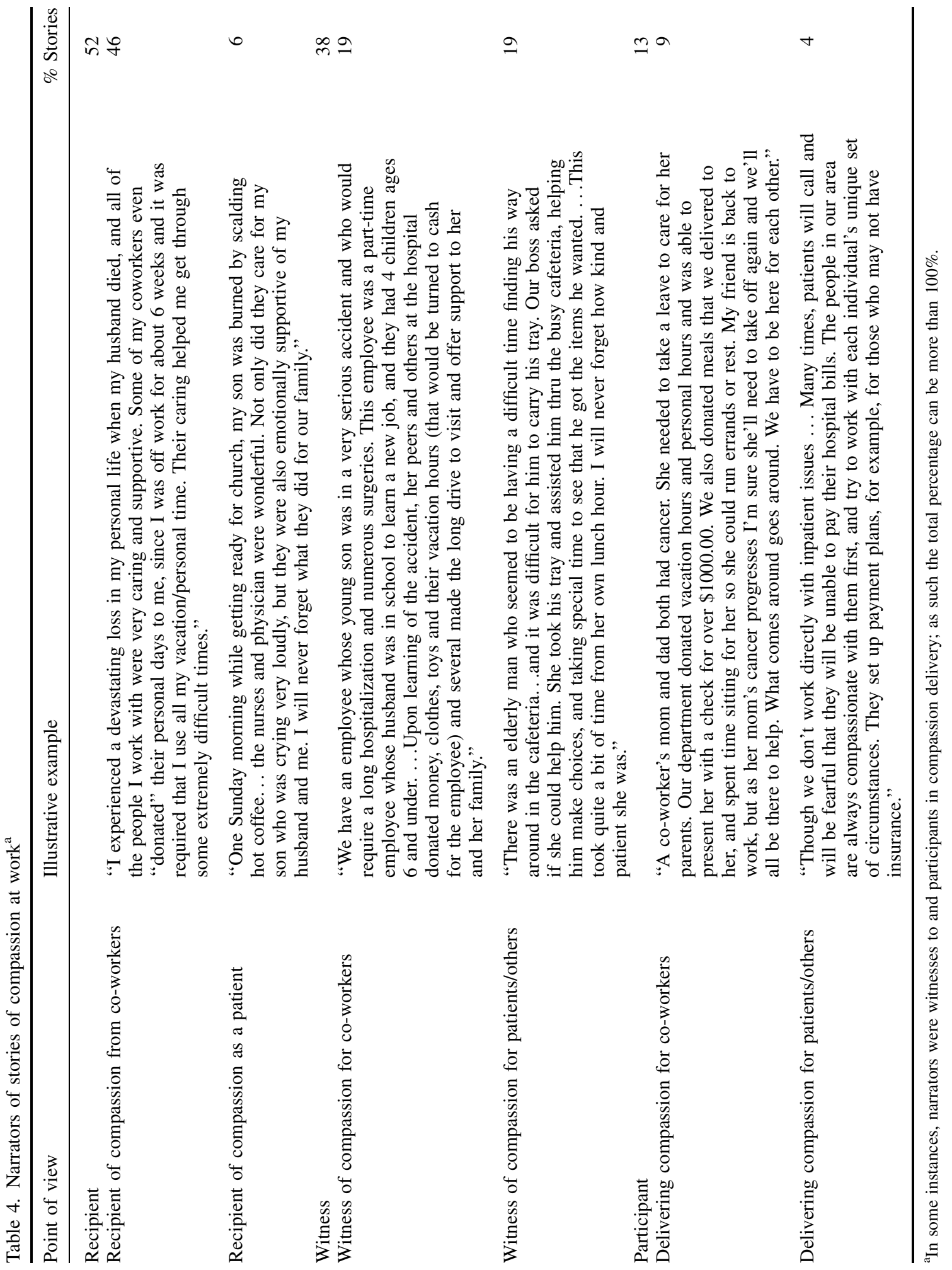


narrators who were recipients of compassion, 46 per cent of stories involve co-workers and 6 per cent involve patients, revealing the complex reality of work life in which employees may also unexpectedly be in a position to receive services from their organization. The proportion of patient care stories rises, however, when narrators are witnesses of compassion, with 19 per cent of stories involving patients. Of those who told stories from the perspective of delivering compassion, 9 per cent involved delivering compassion to co-worker, and only 4 per cent involved delivering compassion to patients.

\section{Forms of compassion at work}

As shown in Table 5, three major categories emerged from coding for the types of actions that people described as compassionate: (1) giving emotional support, (2) giving time and providing flexibility, and (3) giving material goods. While we have portrayed these categories of actions as distinct, in many stories people described an instance of compassion in which actions covered the gamut of emotional and material support as well as offering flexibility and time.

Respondents most often described emotional support, including gestures such as hugs, questions about one's well-being, and verbal expressions of support. An example of this category is given in this story told by Lisa, a nurse in the hospital:

My good friend and fellow nurse was diagnosed with cancer. Everyone on my and her units was extremely supportive of me, with hugs and verbalization as I supported her. They let me verbalize my sad feelings and helped pick me up when I was low.

In many instances, the primary form that compassion took was emotional, often because there was little that could be done to remedy the situation. In Lisa's case, her co-workers could not help to cure her friend, but their expressions of support and their empathetic overtures made a difference nonetheless.

The second category of actions described as compassionate were those that gave the sufferer time or flexibility in ways that went above and beyond what was expected or mandated. Nancy told a story that illustrates this category, when her co-workers responded with compassion to a trigger of job stress:

One Friday later afternoon I was swamped with phone calls to patients and finishing paper work that had to be completed. It was 5:45pm, and I felt close to tears, but tried to hide it. Two co-workers took their coats off and spent 10-15 minutes helping me finish. Their act of compassion was most appreciated. I can't remember feeling like this before or after that day at work. I love my job!

As evidenced in Nancy's story, even a small act of compassion can have a big impact on the person receiving such attention. This type of flexibility takes many forms, such as offers of time for recovery, covering a co-worker's shift, making and delivering food to co-workers' homes, attending funeral services, or going out of one's way to attend to another's suffering. The granting of flexibility is a form of hidden asset that employees can share with each other, which has instrumental and symbolic meaning for those who receive it. In addition, as suggested by research on absence as a coping mechanism (Hackett \& Bycio, 1996), a compassionate act that allows a distressed individual to take time out from work can be highly restorative.

The final category of actions involved the granting of material support such as money, food, gifts, flowers, or cards. John, an outpatient laboratory employee, offered this story that illustrates how material support can become a form of compassion:

A coworker with 7 children, who was only in his mid-thirties, was admitted to the hospital and discovered that he needed immediate heart by-pass surgery. His insurance only gave his family a portion of his normal income, and we knew that it wasn't enough. I set up a tax free trust fund and ended up getting a little over $\$ 5800.00$ in donations - more than enough to cover his losses of being 


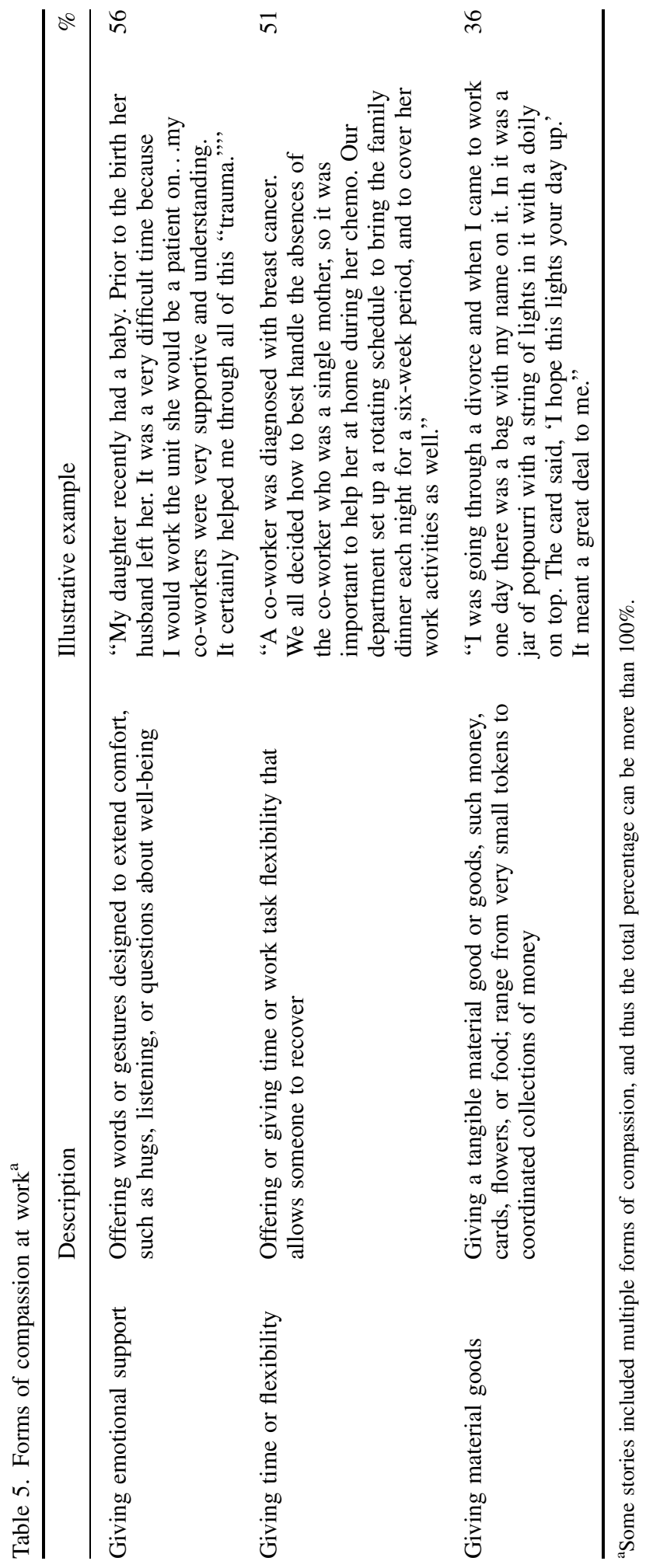

Copyright (C) 2008 John Wiley \& Sons, Ltd. 
off work for the extended period of time. I couldn't believe that our lab, with a total of 75 people, came up with that much money in less than one week's time. It still means a lot to me, knowing that I work with such caring people.

John's story is a vivid depiction of the ways in which co-workers engaged in spontaneous organizing to gather material goods to respond with compassion to someone who was suffering.

\section{Emotions associated with compassion at work}

Respondents on average make one mention of positive emotion per story ${ }^{2}$. A minority of stories (20 per cent) contained no emotion words. The largest category of emotion words was descriptions of the sympathy or empathetic understanding of suffering, in 25 per cent of the stories. The next largest category of emotion words included aroused positive emotion descriptors such as encouraged, glad, happy, joyful, and pleased (18 percent), while non-aroused feelings of being calmed, relaxed, comforted, and consoled were mentioned with similar frequency (17 percent). In addition to the positive emotions associated with experiences of compassion, people described instances of compassion as decreasing their negative emotions, such as feeling less anxious (19 per cent), reduced pain (17 per cent), less shame, intimidation or fear ( 10 per cent), and less sad ( 8 per cent).

\section{The meaning of compassion at work}

Finally, we coded the stories for the kinds of inferences that people made as they made sense of instances of compassion at work. As shown in Table 6, these inferences could be grouped into those relating to the self, to co-workers, and to the overall quality of the work organization. These three categories were mentioned in at least 10 per cent of the compassion stories. In our analysis, each story could feature multiple inferences, as we attempted to capture the full spectrum of meanings that people associated with compassionate acts.

Inferences about the self. As shown in Table 6, 44 per cent of the stories featured an inference about what compassion means to the self. For example, often the narrator appeared to infer that he or she was better able to carry on with his or her life and work, was more capable of managing pain, or could be more fully him or herself at work. An example is given by Julie:

I returned to work after 12 weeks off for maternity leave. My child was still very colicky and I continued to nurse after returning to work. My co-workers always brought up my need to eat lunch first and to use the breast pump even when we were so busy, we weren't all going to eat that day. I never felt as if I was a burden to my co-workers. They felt what I was doing was important (breastfeeding). Their compassion made my decision to continue to breastfeed easier.

Julie's story reveals that the instances of compassion from her co-workers validated her choices and helped her feel like a valued member of her work unit. This category of inferences suggests that in the face of difficulty, the experience of compassion in the workplace can have a lasting impact on how one sees his or herself.

Inferences about co-workers. Table 6 shows that 32 percent of the stories contained an inference about the qualities of the narrator's co-workers as a result of an instance of compassion. For example, in John's story, above, about creating a tax-free fund for an ill co-worker, the story concludes with an

\footnotetext{
${ }^{2}$ Reporting that 100 per cent of stories include positive emotion is somewhat misleading, as this coding allowed multiple words to be counted in each story. The finding is best interpreted as an average of one emotion word per story, with some stories featuring several positive emotion words and some stories featuring none. The figure of 100 percent is generated by this counting procedure, i.e., we counted 162 positive emotion words from a sample of 162 stories.
} 


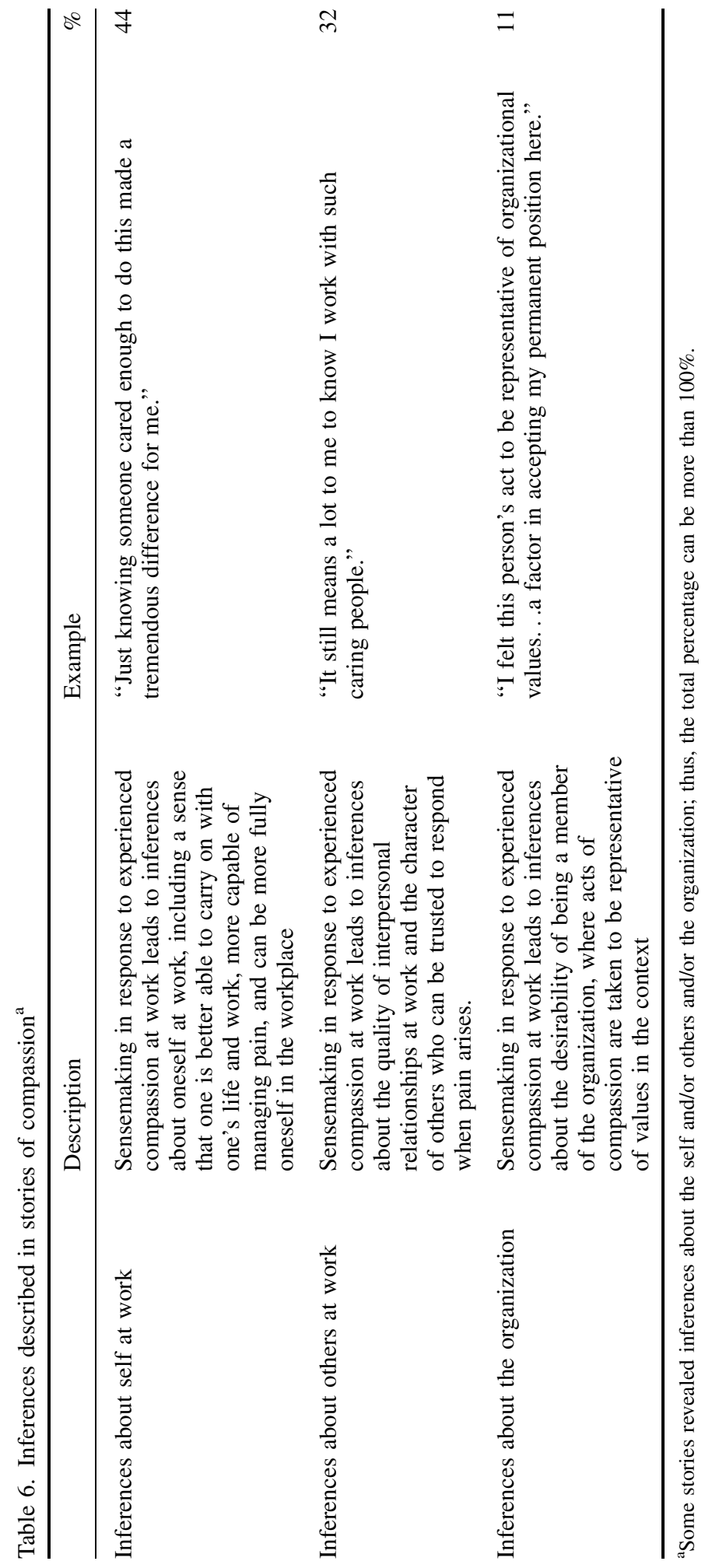

Copyright (C) 2008 John Wiley \& Sons, Ltd. 
inference about his co-workers that results from this episode: "It still means a lot to me, knowing that I work with such caring people." As Weick's (1995) view of sensemaking would suggest, the jolt to a co-worker's life and the unexpected compassion that John witnesses created an occasion for an inference about the positive qualities of his colleagues.

Inferences about the organization. Table 6 shows that 11 percent of the stories in this sample feature an inference about how people saw their organization in the wake of an instance of compassion. Some of them used this experience to answer the question, "What kind of organization do I work for?" and in some cases changed their view. In one example, Andrew translates his sense of being cared for by his work colleagues into pride in his work organization:

Recently I was told my stepbrother had been killed in an auto accident. I called my manager at home to find out what do to about my schedule. My manager was very sympathetic and told me not to worry about any paperwork, she would fill out what was needed so I would not lose any pay. When I returned home, I had already received cards from my manager and coworkers and a plant with a sympathy card from the organization itself. I am proud to work for an organization that is large enough to have the technology and facilities we do, but small enough to know that people are the important part.

Although the acts of compassion described in Andrew's story were carried out by individual organizational members, they are taken to be representative of larger values in the work organization, which contributes to positive feelings about the workplace overall.

\section{When compassion at work is lacking}

Another way to assess the impact of compassion at work is to examine when compassion is not offered to someone who is suffering. Five percent of the stories described a lack of compassion in the workplace provided by respondents who did not differ in terms of average age, gender, modal education level, average tenure, or level in the organization. By looking to these stories we can begin to map the implications for both employees and organizations when compassion is absent. One example comes from a story told by Andrea, a nurse in the hospital:

Over a year ago my mother-in-law passed away. I called my head nurse who I have worked with or for over 24 years to ask her some questions about getting time off and was told, "I have staff that handle this, and I don't want to deal with it." I called her house shift supervisor and she told me I'd have to work an extra day to get the day of the funeral off. ...I reported to work and missed the showing at the funeral home. ... No one offered to help cover me whatsoever that whole week. I got 2 days off only and missed out on a lot.

As Andrea's story describes, when compassion is not extended in times of difficulty, the impact can be devastating. Not only did this failure make it hard for Andrea and her family to get through a painful time, but it also compromised her sense of belonging. As Andrea continued:

Plus my sister-in-law who also works for Fairview but from another area got the entire week off \& had 3 plants arrive from her department. I never received a single call, note, plant or flowers. ... I was hurt and embarrassed when several others noticed the lack of response from my workplace. ...I really believe that my leaving would be of no concern to my present management. Why should I stay on and work hard for an organization that cares little? I've been here over 30 years, and accepted several changes — good and bad. I don't know anymore!

Andrea's story illustrates how a lack of compassion can leave employees feeling disconnected from their co-workers, and even challenge their commitment to the organization. It also reveals that 
employees may have expectations that when personal difficulties arise, co-workers will provide a certain degree of compassion in the form of material gestures or basic words demonstrating emotional support. We cannot know whether the compassion failure described above was an oversight by busy and preoccupied work colleagues, or whether this suffering was noticed but a compassionate response withheld, constituting some mild form of discretionary interpersonal aggression (Glomb \& Liao, 2003). Whatever the case, we can see that when compassion is absent in the wake of pain, it can be seen as both an aggressive individual act and/or as representative of organizational values, which can lead employees to question their commitment and dedication to their work role. Taken together, these stories suggest the power of small acts of compassion, and their absence, to shape people's sense of the workplace.

\section{Discussion}

The findings from Study 2 highlight the value to organizational scholarship of studying how work colleagues respond to each others' pain, and what the experience of compassion feels like and means to those who give, receive, and witness it. The stories in this sample describe a variety of pain triggers, with at least 62 per cent of the stories describing suffering that originated outside the organization. This suggests that despite the frequency with which organizational polices and practices can cause pain (Frost, 2003), the most salient incidents producing a compassionate response are those relating to suffering caused by life events such as death, severe illness, and major family incidents. Perhaps such events are so much more significant than the frustrations and humiliations that often arise in the course of doing one's job, or perhaps these events are more memorable. Given the recent interest in toxic working conditions (Frost, 2003; Maitlis \& Ozcelik, 2004), such questions could benefit from further investigation.

Second, the study reveals the myriad small but important ways in which work colleagues across roles and organizational level express compassion. We have organized these into three categories: providing emotional support, time and flexibility, and material support. In addition, the analysis of stories in Study 2 shows that people craft stories from the perspective of recipient of compassion, participant in providing compassion, and witness to compassion. These findings suggest that experiencing compassion indirectly may be as powerful as receiving it.

The third goal of this study was to investigate the emotional tone of compassion at work by examining the emotions contained in people's narratives. The large proportion of mentions of positive emotion in stories of compassion at work is consistent with the findings from Study 1, that positive emotion mediates the relationship between experienced compassion and other important workplace outcomes.

Finally, we sought to understand how people make sense of compassion at work. Analysis of the stories in Study 2 shows that employees use instances of compassion to make sense of their own ability to contribute and carry on at work, but also to understand their co-workers and their work environment. When compassion is present, individuals make inferences such as "my co-workers are kind and generous people," or "this organization cares about me and its members" that constitute new understandings of themselves, their co-workers, and the organization as a whole. The small number of stories describing co-worker or organizationally induced pain made it difficult to draw conclusions about the kinds of inferences made about co-workers or the organization that occurred in these cases, but it seems likely that individuals would be less prone to make positive meaning about the people or institution that had caused them suffering, despite receiving compassion from others. Certainly, the absence of compassion can have significant impact on employees' constructions of their co-workers and their overall work environment. These findings offer insight into the potential for far-reaching effects of experienced compassion at work, suggesting that the significance of small acts of compassion becomes elaborated through different types of sensemaking. 


\section{Overall Discussion}

This paper explores the understudied topic of compassion at work from two unique but complementary angles: a pilot survey and a qualitative analysis of employees' narratives of compassion at work. Findings from the survey indicate that in this work organization, instances of compassion occur with relative frequency regardless of age, gender, level of education, or status level in the organization. This survey study tested a theoretical model of the relationship between compassion and affective outcomes, showing that compassion at work is associated with more frequent positive emotion and heightened affective commitment.

Findings from a second study add texture to our understanding of the experience of compassion in the workplace. The narratives in Study 2 revealed the wide range of painful experiences - both inside and outside an organization - that trigger compassion, and identified ways in which work colleagues respond by noticing what is happening, feeling empathetic concern, and responding in ways that attempt to alleviate the suffering. These findings also show that in work organizations, compassion is most often a collective rather than an individual response, with multiple co-workers offering task-based help and emotional support, providing time or task flexibility, and/or collecting money and other material support.

We further saw that compassion is associated with a variety of positive emotions, as well as a reduction in negative ones, offering further support for the findings from Study 1. In keeping with our use of the framework provided by affective events theory (Weiss \& Cropanzano, 1996), we showed that compassion is a particularly salient emotional event that provides an important occasion for employee sensemaking. Together, these studies reveal that people who experience compassion at work are deeply affected, both affectively and in terms of their understandings of self, others, and the organization. They also show that these important affective experiences at work are likely to have significant impacts on a variety of longer-term work attitudes, behaviors, and performance-and health-related outcomes.

Compassion represents a form of personal connection that we rarely notice in work organizations and is usually invisible in any formal sense. This is because if compassion "works," it allows people to heal and recover, generating little if any interruption to the normal flow of action and leaving little visible trace of its deep impact. Despite this invisible quality, however, the study of compassion offers several contributions to organizational research.

\section{Contributions of the study}

By highlighting the relational foundation of work organizations, the exploratory studies described here contribute to previous portrayals of organizations as relational systems (Kahn, 1993, 1998, 2001) and sites of social life (Sandelands, 1998, 2003). We have shown the fundamental needs people have for connection and belonging (Baumeister \& Leary, 1995), and revealed how certain interpersonal experiences at work are associated with a sense of being valued by, cared for, connected to, and ultimately committed to their work organizations. In addition, we have provided evidence that the interpersonal actions of work colleagues in the face of pain can be seen as representative of organizational values, contributing to employees' sense that they are supported not only by these particular colleagues but by the larger organization. While research on perceived organizational support suggests that these perceptions are important in shaping a number of outcomes (e.g., Rhoades \& Eisenberger, 2002), it is relatively silent on how interpersonal behaviors contribute to such perceptions. These studies suggest some underlying mechanisms by which acts of compassion generate perceptions of support and strengthen organizational commitment. 
Second, the present study adds to the growing body of research on positive emotion, which to date has been largely reliant on laboratory studies (e.g., Fredrickson \& Joiner, 2002; Isen, 2000). Our field study demonstrates the important relationship between compassion and positive emotion as it plays out in an organizational setting. Beyond measuring aggregate positive emotion, these studies show that those experiencing compassion feel distinct positive emotions, such as pride, gratitude, inspiration, and ease, and respond to a call for the study of specific emotions (Oatley \& Jenkins, 1996; Tiedens \& Linton, 2001) rather than affect in general. Moreover, these findings point to a simple but powerful way of strengthening emotional well-being at work, and as a result, of broadening people's mindsets and building their intellectual, physical, social, and psychological resources (Fredrickson, 1998, 2003). Though preliminary, our findings suggest that the relationship between compassion and positive emotion is an organizational phenomenon worthy of further study.

Third, we contribute to a body of work that, despite the highly emotional nature of many of the cues that trigger sensemaking, has maintained a largely cognitive focus (Weick, Sutcliffe, \& Obstfeld, 2005). In providing evidence that the inferences flowing from interpersonal acts of compassion are steeped in emotion - from the feelings that drive its expression to the emotions that are associated with receiving, witnessing, or participating in a compassion episode-we add to previous work that advocates the inclusion of "emotional sense" in the discussion of sensemaking in organizations (Maitlis, 2007; Patient et al., 2003).

Finally, our study of compassion answers the call from positive organizational behavior (e.g., Luthans, 2002, 2003) and positive organizational scholarship (e.g., Cameron, Dutton \& Quinn, 2003) to pursue a deeper understanding of the conditions that foster positive states in work organizations. A focus on experienced compassion at work shows how small interpersonal acts can contribute to positive outcomes of lasting interest to organizational researchers. Our results invite researchers interested in positive organizational phenomena to study how the skillful impromptu caring that colleagues do in response to pain creates desirable outcomes at the individual level, and how positive behavior such as compassion contributes to beneficial interpretations of the self, of colleagues, and of the organization.

\section{Limitations and future directions}

These two studies must be interpreted in the light of their limitations. First, although we suggest and find support for a theoretical model of the affective effects of compassion at work, the current studies were not experimental designs, and can provide only correlational support for the effects we propose. Second, because of the exploratory nature of these studies, we intentionally kept our model simple; however, it is likely that compassion has much wider ranging consequences in work organizations than those investigated here. For example, while we focused only on the affective component of organizational commitment, it is likely that compassion is also associated with normative commitment, as grateful employees feel more obligated towards an organization in which they have been treated with compassion. Similarly, while we were not able to investigate relationships between compassion and outcomes such as absenteeism, turnover, and recovery time in the present study, the link between compassion and such organizational outcomes clearly offers an important avenue for future research.

A third limitation involves response rates. Although the research team took extraordinary measures to encourage responses, we are limited in our ability to draw general conclusions about the effects of compassion at work because of the low response rate that we obtained. While it is possible that the individuals who participated in this research are those for whom compassion is particularly meaningful, this seems unlikely given considerable variation among respondents in the amount of compassion experienced and in the provision of a compassion narrative. Self-selected participation also 
means that there may be many types of response bias in the data of which we can only be partially aware.

Related to the response rate issue is the timing of the survey, which was distributed just before the 9/ 11 terrorist attacks. This tragic event overshadowed almost everything going on in employees' normal lives, making a survey seem relatively insignificant. In addition to producing a much lower than expected response rate, this timing may have had further effects on the way participants answered the questions. While we cannot fully understand the impact on our respondents of these events, we might speculate that the compassion they had experienced at work suddenly felt quite trivial in relation to the larger acts taking place, as portrayed so vividly in the media. Alternatively, it is possible that the salience of compassionate responses displayed by co-workers to this tragedy-or even our own CompassionFest activities - caused an increase in employees' sense of the general levels of compassion shown in their workplace. The possibility of either of these effects raises important questions about the relationship between one act of compassion and another, and therefore individuals' overall experience of compassion.

Finally, our exploratory research was necessarily limited in the breadth of questions it could tackle. By unpacking the contours of compassion at work, and identifying some key effects of compassion on those who receive, give, and witness it, we have addressed important gaps in the positive organizational behavior literature. At the same time, however, our findings open up other important questions about when and where compassion will be found. Some research has begun to address some of these issues, but pays particular attention to the conditions associated with compassion that is socially coordinated, rather than the informal, spontaneous, and individual acts that form the focus of the present studies (Dutton et al., 2006; Kanov et al., 2004). We suggest, therefore, that an important area for future research in positive organizational behavior lies in the further examination of the conditionsstructural, cultural, and individual — that are most likely to spawn compassion at work.

\section{Conclusion}

We hope that these two views of compassion at work allow organizational scholars and practitioners to see the potency of compassion in work organizations. While compassionate interpersonal acts are rarely large or dramatic, they may become so in the minds of the recipients. In the words of Weick et al. (2005), "smallness does not equate with significance. . .short moments can have large consequences" (p. 5). This paper shows that acts of compassion are moments of everyday human action at work that prompt sensemaking and generate feeling that seeps into people's attitudes and behaviors, and provides support for Frost's (1999) declaration that compassion does, indeed, count.

\section{Acknowledgements}

We thank Susan Ashford, Martha Feldman, and Gretchen Spreitzer for comments on an earlier draft of this paper and attendees at the Center for Positive Organizational Scholarship for their feedback. We would also like to thank the editors of this special issue and our anonymous reviewers for their helpful comments. In addition, we thank the William Russell Kelly Chair and the Edgar F. Kaiser Chair for their support of this project. 


\section{Author biographies}

Jacoba M. Lilius is an assistant professor cross-appointed in the School of Policy Studies and School of Business at Queen's University and received her Ph.D. in Organizational Psychology from the University of Michigan. In addition to her work with the Compassionlab, Jacoba's research focuses on the strategies in which people engage to enable high-quality work under challenging conditions, with a current focus on caregiving occupations.

Monica C. Worline is an assistant professor of organization and management at the Goizueta Business School at Emory University. She received her Ph.D. from the University of Michigan, where she began her work with the Compassionlab. Monica's main topic of study is the way in which the expression of courage unfolds in work settings.

Sally Maitlis is an associate professor of organizational behaviour at the Sauder School of Business at the University of British Columbia. She received her Ph.D. from the University of Sheffield. Alongside her work with the Compassionlab, Sally's research examines the role of emotion in individual and organizational sensemaking and decision making, and social and political aspects of organizational decision making processes. She is particularly interested in narrative and discursive approaches to the study of emotion at work.

Jason M. Kanov is an assistant professor of management in the College of Business and Economics at Western Washington University. He received his Ph.D. from the University of Michigan. His interest in compassion is one aspect of a broader interest in socio-emotional workplace phenomena. His current research examines how relational events, namely instances of interpersonal disconnection, affect individuals, workplace relationships, and the overall social life of work organizations.

Jane E. Dutton is the Robert L. Kahn Distinguished University Professor of Business Administration and Psychology at the Stephen M. Ross School of Business at the University of Michigan and chairperson of the Management and Organizations area. She received her Ph.D. from Northwestern and was previously on the faculty of New York University. Dutton's current research focuses on how organizational conditions enable human thriving. Her research explores compassion, resilience, and energy in work organizations. She is co-founder of the Center for Positive Organizational Scholarship (see http://www.bus.umich.edu/positive/).

The late Peter Frost was the Edgar Kaiser Chair of Organizational Behavior at the Sauder School of Business at the University of British Columbia. He was known as an innovative academic, and his research and teaching focused on the topics of leadership, organizational culture, and emotions in the workplace, culminating in an award-winning book entitled Toxic Emotions at Work. Peter founded the "Compassionlab" (www.compassionlab.com) to advance organizational scholars' knowledge about compassion at work. Peter experienced a fatal recurrence of his cancer in 2004 . We are proud to see this article published posthumously as a tribute to his dedication to the study of compassion in organizations.

\section{References}

Allen, T. D. (2001). Family supportive work environments: The role of organizational perceptions. Journal of Vocational Behavior, 58, 414-435.

Allen, N. J., \& Meyer, J. P. (1990). The measurement and antecedents of affective, continuance, and normative commitment to the organization. Journal of Occupational Psychology, 63, 1-18. 
Baumeister, R., \& Leary, M. (1995). The need to belong: Desire for interpersonal attachments as a fundamental human motivation. Psychological Bulletin, 117, 497-529.

Bentler, P. (1995). EQS structural equation program manual. Los Angeles: BMDP Statistical Software.

Brief, A. P., \& Motowildo, S. J. (1986). Prosocial organizational behaviors. Academy of Management Review, 11, 710-725.

Bruner, J. (1986). Actual minds, possible worlds. Cambridge, MA: Harvard University Press.

Cameron, K. S., Dutton, J. E., \& Quinn, R. E. (2003). Positive Organizational Scholarship: Foundations of a new discipline. San Francisco, CA: Berrett-Koehler Publishers, Inc.

Cialdini, R. B., Borden, R. J., Thorne, A., Walker, M. R., Freeman, S., \& Sloan, L. R. (1976). Basking in reflected glory: Three (football) field studies. Journal of Personality and Social Psychology, 34, 366-375.

Clark, C. (1997). Misery and company: Sympathy in everyday life. Chicago, IL: The University of Chicago Press.

Cohen, J. A. (1960). A coefficient of agreement for nominal scales. Education and Psychological Measurement, 20, 37-46.

Culpepper, R. A. (2000). A test of revised scales for the Meyer and Allen (1991) three-component commitment construct. Educational \& Psychological Measurement, 60, 604-616.

Davis, M. H. (1983). The effects of dispositional empathy on emotional reactions and helping: A multidimensional approach. Journal of Personality, 51, 167-184.

Dutton, J. E. (2003). Energize your workplace: How to build and sustain high-quality connections at work. San Francisco: Jossey-Bass.

Dutton, J. E., Worline, M. C., Frost, P. J., \& Lilius, J. M. (2006). Explaining compassion organizing. Administrative Science Quarterly, 51, 59-96.

Dutton, J. E., Frost, P. J., Worline, M. C., Lilius, J. M., \& Kanov, J. (2002). Leading in times of trauma. Harvard Business Review, January, 54-61.

Figley, C. R. (1995). Compassion fatigue: Toward a new understanding of the costs of caring'. In B. H. Stamm (Ed.), Secondary traumatic stress: Self-care issues for clinicians, researchers, and educators (pp. 3-28). Baltimore, MD: Sidran Press.

Fisher, C. (2002). Antecedents and consequences of real-time affective reactions at work. Motivation and Emotion, $26,3-30$.

Fiske, S. T., \& Depret, E. (1999). Perceiving the powerful: Intriguing individuals versus threatening groups. Journal of Experimental Social Psychology, 35, 461-480.

Folkman, S., \& Moskowitz, J. T. (2000). Positive affect and the other side of coping. American Psychologist, 55, 647-654.

Fredrickson, B. L. (1998). What good are positive emotions? Review of General Psychology, 2, 300-319.

Fredrickson, B. L. (2003). The value of positive emotions: The emerging science of positive psychology in understanding why it's good to feel good. American Scientist, 91, 330-335.

Fredrickson, B. L., \& Joiner, T. (2002). Positive emotions trigger upward spirals toward emotional well-being. Psychological Science, 13, 172-175.

Fredrickson, B. L., Tugade, M. M., Waugh, C. E., \& Larkin, G. R. (2003). What good are positive emotions in crises? A prospective study of resilience and emotions following the terrorist attacks on the United States on September 11, 2001. Journal of Personality and Social Psychology, 84, 365-376.

Frost, P. J. (1999). Why compassion counts. Journal of Management Inquiry, 8, 127-133.

Frost, P. J. (2003). Toxic emotions at work: How compassionate managers handle pain and conflict. Boston, MA: Harvard Business School Press.

Frost, P. J., Dutton, J. E., Maitlis, S., Lilius, J. M., Kanov, J. M., \& Worline, M. C. (2006). Seeing organizations differently: Three lenses on compassion. In C. Hardy, S. Clegg, T. Lawrence, \& W. Nord (Eds.), Handbook of organization studies (2nd ed., pp. 843-866.), London: Sage.

Frost, P. J., Dutton, J. E., Worline, M. C., \& Wilson, A. (2000). Narratives of compassion in organizations. In S. Fineman (Ed.), Emotion in organizations (pp. 25-45). London: Sage.

Glomb, T. M., \& Liao, H. (2003). Interpersonal aggression in work groups: Social influence, reciprocal, and individual effects. Academy of Management Journal, 46, 486-496.

Hackett, R., \& Bycio, P. (1996). An evaluation of employee absenteeism as a coping mechanism for hospital nurses. Journal of Occupational and Organizational Psychology, 69, 327-338.

Hallowell, E. M. (1999). The human moment at work. Harvard Business Review, 77, 58-66.

Harvey, J. H. (2001). The psychology of loss as a lens to a positive psychology. American Behavioral Scientist, 44 , 838-853.

House, J. S. (1981). Work stress and social support. Reading, MA: Addison-Wesley. 
Hu, L., \& Bentler, P. (1999). Cutoff criteria for fit indexes in covariance structure analysis: Conventional criteria versus new alternatives. Structural Equation Modeling, 6, 1-55.

Isen, A. M. (2000). Positive affect and decision making. In M. Lewis, \& J. Haviland-Jones (Eds.), Handbook of emotions (2nd ed., pp. 417-435.), New York: Guilford.

Izard, C. E. (1977). Human emotions. New York: Plenum Press.

Kahn, W. A. (1993). Caring for the caregivers: Patterns of organizational caregiving. Administrative Science Quarterly, 38, 539-563.

Kahn, W. A. (1998). Relational systems at work. In B. M. Staw, \& L. L. Cummings (Eds.), Research in organizational behavior (Vol. 20, pp. 39-76). New York: Elsevier Science.

Kahn, W. A. (2001). Holding environments at work. Journal of Applied Behavioral Science, 37, 260-279.

Kahn, W. A. (2005). Holding fast: The struggle to create resilient caregiving organizations. New York: Brunner-Routledge.

Kanov, J. M., Maitlis, S., Worline, M. C., Dutton, J. E., Frost, P. J., \& Lilius, J. M. (2004). Compassion in organizational life. American Behavioral Scientist, 47, 808-827.

Krippendorf, K. (2004). Content analysis: An introduction to its methodology (2nd ed.). Thousand Oaks, CA: Sage. Leguin, U. (1969/1976). The left hand of darkness. New York, NY: Ace Books.

Lim, S. (2005). Helping or hurting? The impact of supervisory support in the workplace. Unpublished Doctoral Dissertation, University of Michigan.

Luthans, F. (2002). The need for and meaning of positive organizational behavior. Journal of Organizational Behavior, 23, 695-706.

Luthans, F. (2003). Positive organizational behavior (POB): Implications for leadership and HR development and motivation. In R. M. Steers, L. W. Porter, \& G. A. Bigley (Eds.), Motivation and leadership at work (pp. 178-195). New York: McGraw-Hill/Irwin.

Maitlis, S. (2007). Meeting emotion: The role of emotion in top management team politics. Working paper, University of British Columbia.

Maitlis, S., \& Ozcelik, H. (2004). Toxic decision processes: A study of emotion and organizational decision making. Organizational Science, 15, 375-393.

Meyer, J. P., \& Allen, N. J. (1991). A three-component conceptualization of organizational commitment. Human Resource Management Review, 1, 61-89.

Miller, K. I. (2007). Compassionate communication in the workplace: Exploring processes of noticing, connecting, and responding. Journal of Applied Communication Research, 35, 223-245.

Miller, J. B., \& Stiver, I. P. (1997). The healing connection: How women form relationships in therapy and life. Boston, MA: Beacon Press.

Molinsky, A., \& Margolis, J. (2005). Necessary evils and interpersonal sensitivity in organizations. Academy of Management Review, 30, 245-268.

Oatley, K., \& Jenkins, J. M. (1996). Understanding emotions. Cambridge, MA: Blackwell.

Ochs, E., \& Capps, L. (2001). Living narrative: Creating lives in everyday storytelling. Cambridge, MA: Harvard University Press.

Patient, D., Lawrence, T. B., \& Maitlis, S. (2003). Understanding workplace envy through narrative fiction. Organization Studies, 24, 1015-1044.

Rafaeli, A., \& Sutton, R. I. (1987). Expression of emotion as part of the work role. Academy of Management Review, 12, 23-37.

Rainer, J. P. (2000). Compassion fatigue: When caregiving begins to hurt. In L. Vandecreek, \& T. Jackson (Eds.), Theory and clinical practice: A source book (pp. 441-453). Sarasota, FL: Professional Resource Press.

Raykov, T., Tomer, A., \& Nesselroade, J. R. (1991). Reporting structural equation modeling results in psychology and aging: Proposed guidelines. Psychology and Aging, 6, 499-503.

Reich, W. T. (1989). Speaking of suffering: A moral account of compassion. Soundings, 72, 83-108.

Rhoades, L., \& Eisenberger, R. (2002). Perceived organizational support: A review of the literature. Journal of Applied Psychology, 87, 698-714.

Rhoades, L., Eisenberger, R., \& Armeli, S. (2001). Affective commitment to the organization: The contribution of perceived organizational support. Journal of Applied Psychology, 86, 825-836.

Riessman, C. K. (1993). Narrative analysis. Newbury Park, CA: Sage Publications.

Russell, J. A. (1980). A circumplex model of affect. Journal of Personality and Social Psychology, 39, 1161-1178.

Sandelands, L. E. (1998). Feeling and form in social life. Lanham, MD: Rowman \& Littlefield Publishers, Inc.

Sandelands, L. E. (2003). Thinking about social life. Lanham, MD: University Press of America.

Smith, A. C., \& Kleinman, S. (1989). Managing emotions in medical school: Students' contacts with the living and the dead. Social Psychology Quarterly, 52, 56-69. 
Smith, C. A., Organ, D. W., \& Near, J. P. (1983). Organizational citizenship behavior: Its nature and antecedents. Journal of Applied Psychology, 68, 653-663.

Soygal Rinpoche (1992). The Tibetan book of living and dying. London: Rider Books.

Strauss, A., \& Corbin, J. (1998). Basics of qualitative research: Techniques and procedures for developing grounded theory, (2nd ed.). Thousand Oaks, CA: Sage.

Tiedens, L. Z., \& Linton, S. (2001). Judgment under emotional certainty and uncertainty: The effects of specific emotions on information processing. Journal of Personality and Social Psychology, 81, 973-988.

Weick, K. E. (1995). Sensemaking in organizations. Thousand Oaks: Sage Publications.

Weick, K. E., Sutcliffe, K. M., \& Obstfeld, D. (2005). Organizing and the process of sensemaking. Organization Science, 16, 409-421.

Weiss, H. M., \& Cropanzano, R. (1996). Affective events theory: A theoretical discussion of the structure, causes, and consequences of affective expereiences at work. In B. M. Staw, \& L. L. Cummings (Eds.), Research in Organizational Behavior (Vol. 18, pp. 1-74). New York: Elsevier Science.

Zaslow, J. (2002). Putting a price tag on grief. Wall Street Journal, November 20: Section D, 1.

Zellars, K. L., \& Perrewe, P. L. (2001). Affective personality and the content of emotional social support. Journal of Applied Psychology, 86, 459-467.

\section{Appendix A: Contextual Sidebar}

Fairview Health System is a not-for-profit, community owned health system that encompasses a full hospital with an emergency medicine center and over 400 beds, along with numerous satellite clinics and specialty services. A critical aspect of Fairview's mission is to assure members of the community that they do not have to travel far to receive quality healthcare.

\section{History of the organization}

Fairview Hospital was founded in the early 1900's by a concerned member of the local community who wanted to ensure that health services would be locally available. Built on donated land, the hospital has maintained its status as a regional community-based healthcare provider ever since. The hospital merged with another local hospital in the early 1980's, as population growth and changing technology made it necessary to build a newer and more modern facility. Today the Fairview Health System growing regional comprehensive healthcare provider, and in 2007, was honored for significant improvements in overall inpatient satisfaction scores over the last 2 years.

\section{Organizational Culture}

The espoused values at Fairview include compassion, competence, diversity, integrity service, teamwork, and quality. Fairview treats a diversity of patients, including those with little financial means. As a result, values at Fairview center on care, compassion, and treating others with dignity. Like any busy healthcare organization, however, Fairview suffers from shortages of trained nursing staff and a workplace that offers significant stress. Although it has many long-time employees, Fairview 
experiences significant turnover rates as a result of difficult shift work, staff shortages, and other difficult working conditions.

\section{Timing of the study}

We distributed our study materials on 6 September 2001. Unbeknownst to us, of course, on 11 September 2001, hijackers took over planes in the largest domestic act of terrorism in US history. We believe that the events of 11 September significantly impacted the response rates of our study by absorbing people's time and attention elsewhere. At the same time, those events confirmed the importance of this research topic and redoubled our conviction that it is critical for organizational scholars to know more about the means by which healing and compassion take place at work. 